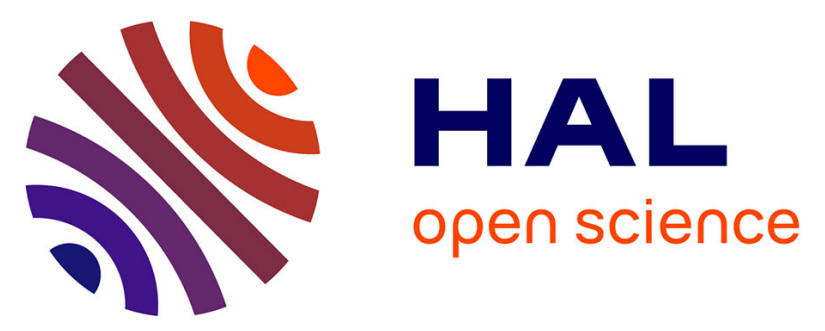

\title{
DELETIONS AND REARRANGEMENTS OF THE H19/IGF2 ENHANCER REGION IN PATIENTS WITH SILVER-RUSSELL SYNDROME AND GROWTH RETARDATION
}

\author{
Karen Grønskov, Rebecca L Poole, Johanne M. D. Hahnemann, Jennifer \\ Thomson, Zeynep Tumer, Karen Brondum-Nielsen, Rinki Murphy, Kirstine \\ Ravn, Linea Melchior, Alma Dedic, et al.
}

\section{- To cite this version:}

Karen Grønskov, Rebecca L Poole, Johanne M. D. Hahnemann, Jennifer Thomson, Zeynep Tumer, et al.. DELETIONS AND REARRANGEMENTS OF THE H19/IGF2 ENHANCER REGION IN PATIENTS WITH SILVER-RUSSELL SYNDROME AND GROWTH RETARDATION. Journal of Medical Genetics, 2011, 48 (5), pp.308. 10.1136/jmg.2010.086504 · hal-00604048

\section{HAL Id: hal-00604048 https://hal.science/hal-00604048}

Submitted on 28 Jun 2011

HAL is a multi-disciplinary open access archive for the deposit and dissemination of scientific research documents, whether they are published or not. The documents may come from teaching and research institutions in France or abroad, or from public or private research centers.
L'archive ouverte pluridisciplinaire HAL, est destinée au dépôt et à la diffusion de documents scientifiques de niveau recherche, publiés ou non, émanant des établissements d'enseignement et de recherche français ou étrangers, des laboratoires publics ou privés. 
1 Deletions and rearrangements of the H19/IGF2 enhancer region in patients with Silver-

2 Russell syndrome and growth retardation

3

4 Karen Grønskov, ${ }^{1, *}$ Rebecca L. Poole, ${ }^{2,3}$ Johanne M. D. Hahnemann, ${ }^{1}$ Jennifer Thomson, ${ }^{4}$

5 Zeynep Tümer, ${ }^{1}$ Karen Brøndum-Nielsen, ${ }^{1,5}$ Rinki Murphy, ${ }^{6}$ Kirstine Ravn, ${ }^{1}$ Linea

6 Melchior, ${ }^{1}$ Alma Dedic, ${ }^{1}$ Birgitte Dolmer, ${ }^{7}$ I Karen Temple, ${ }^{2,3}$ Susanne E. Boonen, ${ }^{1,8}$

7 Deborah Mackay ${ }^{2,3}$

8

9 1) Center for Applied Human Molecular Genetics, The Kennedy Center, 2600 Glostrup,

10 Denmark

11 2) Wessex Genetics Service, Southampton University Hospitals Trust, Southampton SO16

125 YA and Salisbury Hospital NHS Foundation Trust, Salisbury SP2 8BJ, UK

13 3) Division of Human Genetics, University of Southampton, Tremona Road, Southampton

14 SO16 6YD, UK

15 4) Yorkshire Regional Clinical Genetics Service, Chapel Allerton Hospital, Harehills Lane,

16 Leeds LS7 4SA, UK

17 5) Genetic Counseling Clinic, The Kennedy Center, 2600 Glostrup, Denmark

18 6) Faculty of Medical and Health Sciences, Universíty of Auckland, 92019 Auckland, New

19 Zealand

20 7) Department of Pediatrics, Næstved Hospital, 4700 Næstved, Denmark

21 8) The Wilhelm Johannsen Centre for Functional Genome Research, University of

22 Copenhagen, 2200 Copenhagen, Denmark

23

24 CORRESPONDING AUTHOR 
1 K Grønskov, The Kennedy Center, Gl. Landevej 7, 2600 Glostrup, Denmark

2 kag@kennedy.dk, phone: +45 43260156, fax: +45 43431130

3

\section{KEYWORDS}

5 Silver-Russell syndrome, H19 enhancer, deletion, methylation

6

7 WORD COUNT

$8 \quad 1936$

9 


\section{ABSTRACT}

2 Silver-Russell syndrome is characterized by pre- and postnatal growth retardation,

3 dysmorphic facial features and body asymmetry. In 35-60\% of SRS cases the paternally-

4 methylated imprinting control region (ICR) upstream of the $\mathrm{H19}$ gene (H19-ICR) is

5 hypomethylated, leading to down regulation of IGF2 and biallelic expression of H19. H19

6 and IGF2 are reciprocally-imprinted genes on chromosome $11 \mathrm{p} 15$. The expression is

7 regulated by the imprinted methylation of the ICR, which modulates the transcription of H19

8 and $I G F 2$ facilitated by enhancers downstream of $H 19$. A promoter element of $I G F 2$,

9 IGF2P0, is differentially-methylated equivalently to the H19-ICR, though in a small number

10 of SRS cases this association is disrupted, i.e. hypomethylation affects either H19-ICR or

11 IGF2P0.

12 Here we present three pedigrees associated with hypomethylation of IGF2P0 in the probands,

13 two with paternally-derived deletions, and one with a balanced translocation of inferred

14 paternal origin. They all have a breakpoint within the H19/IGF2 enhancer region. One

15 proband has severe growth retardation, the others have SRS. This is the first report of

16 paternally derived structural chromosomal mutations in $11 \mathrm{p} 15$ causing SRS. We propose that

17 these cases define a novel etiology of the growth retardation in SRS, namely, dissociation of

18 IGF2 from its enhancers.

19

20 


\section{INTRODUCTION}

2 Silver-Russell syndrome (SRS, MIM 180860) is a genetically and clinically heterogeneous

3 condition characterized by intrauterine and postnatal growth retardation, dysmorphic facial

4 features and body asymmetry [1]. 35-60\% of SRS cases show hypomethylation of the H19

5 imprinting control region (H19-ICR; Fig. 1a) at11p15, which is believed to result in reduced

6 expression of IGF2 (MIM 147470) [2-4]. The underlying causes of hypomethylation include

7 mosaic maternal uniparental disomy (UPD) of chromosome 11 [5], maternal duplication of

$8 \quad 11 \mathrm{p} 15$ [6, 7], and possibly gene mutations of H19-ICR [8], but is unknown in most cases. In

9 most SRS patients hypomethylation occurs at both H19-ICR and IGF2P0, but is occasionally

10 restricted to H19-ICR or IGF2P0 [9].

11 The H19-ICR is located within the H19 promoter and is normally methylated on the

12 paternally-derived allele. H19 (MIM 103280) encodes a maternally-expressed non-coding

13 RNA while IGF2 encodes the paternally-expressed growth factor IGF-II. In mice the

14 endodermal enhancers of $I G F 2$ are located $+10 \mathrm{~kb}$ from $H 19$ transcription start site; skeletal

15 muscle and mesodermal enhancers are located at $+35 \mathrm{~kb}$ and other mesodermal enhancers at

$16+120 \mathrm{~kb}$ [10]. The interaction of these enhancer sequences with the promoters of $H 19$ or

17 IGF2 is modulated by CTCF for which the H19-ICR contains seven potential binding sites

18 [11]. CTCF binding to unmethylated H19-ICR prevents interaction between the IGF2

19 promoter and enhancers, while methylation of the H19-ICR prevents CTCF binding, enabling

20 the enhancers to interact with the IGF2 promoter. Naturally occurring structural anomalies in

21 the enhancer region of $H 19 / I G F 2$ in patients are very informative in testing the hypothesis of

22 complex imprinting and competing enhancer regulation of $H 19$ and $I G F 2$ and ultimately help

23 to more clearly define the roles of these genes in humans. We report here for the first time

24 SRS patients with chromosomal structural mutations in the H19/IGF2 enhancer region. 


\section{METHODS}

\section{Patients}

3 Patient 1 was referred for SRS testing at the age of 2 years due to pre- and postnatal growth

4 retardation, characteristic dysmorphic features, congenital anomalies and failure to thrive.

5 Patient 2 was referred at age 14 weeks with pre- and postnatal growth retardation, typical

6 facial features and severe feeding difficulties. Subsequently his sister (patient 3) presented

7 neonatally with the same clinical features. Patient 4 was identified after karyotyping due to

8 recurrent miscarriages. She had pre- and postnatal growth retardation and atypical diabetes,

9 but there was no clinical suspicion of SRS. Informed consent for the investigations performed

10 and publication was obtained for all patients. Patients 1 and 4 were recruited via the initial

11 diagnostic testing, while patients 2 and 3 were recruited into the research study "Imprinting

12 Disorders Finding Out Why?" (IDFOW), approved by Southampton and South West

13 Hampshire Research Ethics committee 07/H0502/85.

\section{Molecular genetic investigations}

16 Karyotyping was performed on cultured lymphocytes using standard techniques.

17 Flourescence-in-situ-hybridization (FISH) analysis was performed on metaphases by standard

18 techniques using BAC and fosmids clones. Genomic DNA was extracted from blood

19 leukocytes by standard procedures.

$21 \quad$ MLPA

22 MLPA analysis was performed by methylation-specific MLPA kit ME030 version B1 from

23 MRC-Holland (Amsterdam, The Netherlands) following the manufacturer's instructions. 250

24 ng of DNA was used for analysis. 
1 Pyrosequencing

2 Genomic DNA $(2 \mu \mathrm{g})$ was bisulphite treated using the EZ-DNA Methylation ${ }^{\mathrm{TM}}$ kit, according

3 to manufacturer's instructions (Zymo Research, Orange, CA USA), except that DNA was

4 eluted in $50 \mu \mathrm{l}$ of elution buffer and $50 \mu \mathrm{l}$ of TE $\mathrm{pH}$ 8.0.

5 Pyrosequencing assays of bisulphite- induced C/T polymorphisms [12] for H19 and IGF2P0

6 were designed using Biotage Assay Design Software ${ }^{\mathrm{TM}}$ v1.0.6 (Biotage, Uppsala, Sweden)

7 and performed essentially as previously described [13]. Briefly, primary amplification

8 reactions (50 $\mu$ l, performed in duplicate) contained forward and reverse primers, one of which

9 was biotinylated, Titanium Taq and buffer (Clontech, Mountain View, Ca. USA), and 20ng

10 bisulphite-treated DNA. After 45 amplification cycles, $20 \mu 1$ single-stranded biotinylated PCR

11 products were pyrosequenced using Pyrosequencing Gold Reagents (Biotage) according to

12 the manufacturer's instructions. The percentage methylation at each $\mathrm{CpG}$ site was determined

13 by AQ software. AQ levels $>5 \%$ were indistinguishable from background fluorescence. In

14 each pyrosequencing assay, a bisulphite treatment control was included in the form of a

15 cytosine not in a $\mathrm{CpG}$ dinucleotide; this would be expected to be converted entirely to uracil.

16 Primer sequences were: H19 pyrosequencing: forward

17 GTATAGTATATGGGTATTTTTGGAGG, reverse

18 CCATAAATATCCTATTCCCAAATAACC (bio); sequencing

19 GTTTYGGGTTATTTAAGTT. This amplifies the region chr11: 1977625-1977877.

20 IGF2(P0) pyrosequencing: forward TGAGGATGGGTTTTTGTTTGGTAT; reverse

21 TCCTCAATCCACCCAAAATAATAT (bio); sequencing

22 AAAAGTTATTGGATATATAGT.

23

24 Array CGH analysis 
1 Array CGH analysis (aCGH) used a custom 8 X 60K Agilent array (Agilent Technologies,

2 South Queensferry, UK) designed to densely cover known human imprinted loci. Probes

3 were designed using Agilent Technologies' e-Array design tool with the following filters

4 applied: Tm filter, similarity filter and catalog probe preference. Across the region

5 chr11:1,674,000-2,979,000 (hg18) probes were tightly tiled to provide maximum resolution

6 with an average spacing of 50nt. The remainder of chr11 was represented by Agilent aCGH

7 control probes, which provide a genome-wide backbone to enable efficient normalization.

8 aCGH was performed according to the manufacturer's instructions. Briefly, 500ng of blood

9 genomic DNA was labeled using the genomic DNA enzymatic labeling kit, hybridized to the

10 array for 24 hours and subsequently washed. Arrays were scanned using an Agilent

11 Technologies' DNA microarray scanner G2539A and data extracted using Agilent

12 Technologies' Feature Extraction software version 10.5.1. Duplications and deletions were

13 mapped and end points determined by Agilent Technologies' DNA Analytics software

14 version 4.0 with the following settings: data was analyzed using the ADM-2 Algorithm with

15 a threshold of 6.0 using the DLR error model, with fuzzy zero turned on and the continuous

16 moving average applied.

18 Web resources

19 Online Mendelian Inheritance in Man (OMIM), http://www.ncbi.nlm.nih.gov/Omim/

20 UCSC Human Genome Database Build hg18, March 2006, http://www.genome.ucsc.edu

21 Database of Genomic Variants (DGV): http://projects.tcag.ca/variation/?source=hg18

\section{RESULTS}

24 The clinical features of the patients are summarized in Table 1. Cytogenetic analysis of

25 patient 1 showed a normal karyotype, 46,XY while MLPA analysis showed deletion of $H 19$ 
1 and part of H19-ICR (Fig. 1a); the peak height of the deleted probes suggested mosaicism,

2 while MLPA analysis of parental DNA was normal, suggesting that the deletion had arisen de

3 novo. Microsatellite analysis showed reduced dosage ratios of D11S4046 (paternal:maternal

4 ratio 1:2.3) consistent with mosaicism (Fig. 1c). Cytogenetic analysis of patients 2 and 3

5 revealed a pericentric inversion of chromosome 11 (karyotypes 46,XY,inv(11)(p15.5q21)pat

6 and 46,XX,inv(11)(p15.5q21)pat, respectively), inherited in both children from their

7 phenotypically normal father. FISH analysis showed a split signal using BAC clone RP11-

8 534I22, while fosmids W12-1875E5 and W12-1660M14 hybridized to 11p and 11q,

9 respectively (Fig. 1a and Fig. 1d) mapping the 11p15.5 breakpoint to chr11:1,862,216-

$101,921,555(\mathrm{hg} 18)$.

11 Patient 4 had a balanced translocation (karyotype 46,XX,t(1;11)(p36.22;p15.5)). FISH

12 analysis mapped the 11p15.5 breakpoint between W12-1875E5 and W12-1660M14 [14].

13 Paternal origin of the translocation was inferred through karyotyping of the patient's mother,

14 who had a normal karyotype, and the patient's daughter, who had the same translocation as

15 the patient but normal growth.

16 DNA methylation analysis showed partial hypomethylation of both H19-ICR and IGF2P0 in

17 patient 1 . In patients 2,3 and 4 IGF2P0 was partially hypomethylated while the methylation

18 of H19-ICR was in the normal range (Fig. 1b).

19 All four patients were analyzed by array CGH (aCGH). In patient $1 \mathrm{aCGH}$ showed a $58.8 \mathrm{~kb}$

20 deletion (chr11:1,918,222-1,977,026 (hg18)) encompassing the endodermal, skeletal muscle

21 specific and part of the mesodermal enhancers, as well as H19 and part of H19-ICR including

22 the seventh CTCF binding site, but not the two repeat blocks (Fig. 1a), though the log

23 intensity difference suggested a mosaic deletion. In patients 2 and 3 aCGH showed an $8.8 \mathrm{~kb}$

24 deletion (chr11:1,918,312-1,927,132 (hg18)) overlapping with the mesodermal enhancer.

25 Deletions partially overlapping with the above deletions have been registered as rare 
1 variations in apparently normal individuals (http://projects.tcag.ca/variation/?source=hg18)

2 but the parental origin of these deletions are unknown. aCGH did not reveal any deletion in

3 patient 4.

\section{DISCUSSION}

6 We present three pedigrees with disruption of the shared H19/IGF2 enhancer region and

7 separation of the mesodermal enhancers from $I G F 2$, one by deletion, one by an inversion

8 breakpoint accompanied by deletion, and one by breakpoint of an apparently balanced

9 translocation. IGF2 expression was reduced in mesodermal tissue in patient 4 [14].

10 Previously, the small stature of patient 4 was unaccounted for, but we now hypothesize that

11 hypomethylation of IGF2-P0 due to the separation of IGF2 from its enhancers causes growth

12 retardation. The deletion in patient 1 may truncate these enhancers and moreover reduces

13 their distance from $I G F 2$ by $50 \%$, thus potentially affecting the local three-dimensional

14 structure of the DNA and hence its function. We therefore suppose that the mesodermal

15 enhancers are non-functional in all four patients. It is interesting that all four patients are

16 growth-retarded, but only patients 1,2 and 3, who harbor deletions including the sequence

17 chr11:1,918,312-1,927,132 (hg18), presented with the clinical diagnosis of SRS. One

18 interpretation of this observation is that reduced $I G F 2$ expression from mesodermal

19 enhancers is responsible for only the growth retardation seen in SRS, while other genetic or

20 epigenetic defects cause the other phenotypic traits of SRS. Alternatively, given that SRS is a

21 disorder with marked clinical heterogeneity it may be that patient 4 showed an atypical

22 presentation.

23 It was striking that all patients showed hypomethylation of IGF2P0, while hypomethylation

24 of the H19-ICR was observed only in patient. This observation suggests that IGF2P0

25 methylation may not directly depend on H19-ICR methylation in cis, but may instead reflect 
1 the promoter activity of IGF2P0 per se, and be established as a consequence of its interaction

2 with distant $I G F 2$ enhancers. Disruption of the enhancer region represents a possible

3 explanation of rare SRS cases with hypomethylation restricted to IGF2P0 [9].

4 The effects of deletions and mutations in the $H 19$ region depend not only on their parent of

5 origin, but also on their localization. Deletions or mutations of H19-ICR described to date are

6 apparently without phenotypic effect when on the paternal allele, whereas in maternal

7 inheritance they are associated with the overgrowth disorder Beckwith-Wiedemann syndrome

8 (MIM 130650) $[15,16]$. Thus, we hypothesize that a paternal deletion of $H 19$, such as seen in

9 patient 1, may be of less clinical significance than the separation of IGF2 from its enhancers.

10 For the enhancer region, no data have hitherto been presented in humans; however, mice with

11 paternally inherited deletions were $80 \%$ of normal size whereas mice with maternal deletions

12 were of normal size [17]. We predict that detailed characterization of the $I G F 2$ promoter and

13 enhancer elements in humans will uncover further genetic and epigenetic changes that

14 predispose to growth retardation and/or SRS. Moreover, we confirm that IGF2P0

15 hypomethylation is found in a proportion of SRS cases with normal H19-ICR methylation.

16 Therefore, in agreement with Bartholdi et al. [9] we suggest that IGF2P0 methylation

17 analysis should be included in standard molecular testing for SRS.

19 ACKNOWLEDGMENTS

20 MLPA was performed by Judy Boe Rasmussen, The Kennedy Center; FISH was performed

21 by Viv Maloney, Wessex Genetics Service. Jette Bune Rasmussen performed the graphic

22 work.

\section{COMPETING INTERESTS}

25 The authors declare no competing interests 
(1) Abu-Amero S, Monk D, Frost J, Preece M, Stanier P, Moore GE. The genetic aetiology of Silver-Russell syndrome. J Med Genet 2008 Apr;45(4):193-9.

\section{Reference List}

(2) Eggermann T, Schonherr N, Meyer E, Obermann C, Mavany M, Eggermann K, Ranke MB, Wollmann HA. Epigenetic mutations in 11p15 in Silver-Russell syndrome are restricted to the telomeric imprinting domain. J Med Genet 2006 Jul;43(7):615-6.

(3) Gicquel C, Rossignol S, Cabrol S, Houang M, Steunou V, Barbu V, Danton F, Thibaud N, Le MM, Burglen L, Bertrand AM, Netchine I, Le BY. Epimutation of the telomeric imprinting center region on chromosome 11p15 in Silver-Russell syndrome. Nat Genet 2005 Sep;37(9):1003-7.

(4) Netchine I, Rossignol S, Dufourg MN, Azzi S, Rousseau A, Perin L, Houang M, Steunou V, Esteva B, Thibaud N, Demay MC, Danton F, Petriczko E, Bertrand AM, Heinrichs C, Carel JC, Loeuille GA, Pinto G, Jacquemont ML, Gicquel C, Cabrol S, Le BY. 11p15 imprinting center region 1 loss of methylation is a common and specific cause of typical Russell-Silver syndrome: clinical scoring system and epigenetic-phenotypic correlations. J Clin Endocrinol Metab 2007 Aug;92(8):314854.

(5) Bullman H, Lever M, Robinson DO, Mackay DJ, Holder SE, Wakeling EL. Mosaic maternal uniparental disomy of chromosome 11 in a patient with Silver-Russell syndrome. J Med Genet 2008 Jun;45(6):396-9.

(6) Eggermann T, Meyer E, Obermann C, Heil I, Schuler H, Ranke MB, Eggermann K, Wollmann HA. Is maternal duplication of $11 \mathrm{p} 15$ associated with Silver-Russell syndrome? J Med Genet 2005 May;42(5):e26.

(7) Eggermann T, Spengler S, Bachmann N, Baudis M, Mau-Holzmann UA, Singer S, Rossier E. Chromosome 11p15 duplication in Silver-Russell syndrome due to a maternally inherited translocation $\mathrm{t}(11 ; 15)$. Am J Med Genet A 2010 Jun;152A(6):1484-7.

(8) Demars J, Shmela ME, Rossignol S, Okabe J, Netchine I, Azzi S, Cabrol S, Le CC, David A, Le BY, El-Osta A, Gicquel C. Analysis of the IGF2/H19 imprinting control region uncovers new genetic defects, including mutations of OCT-binding sequences, in patients with 11p15 fetal growth disorders. Hum Mol Genet 2010 Mar 1;19(5):80314.

(9) Bartholdi D, Krajewska-Walasek M, Ounap K, Gaspar H, Chrzanowska KH, Ilyana H, Kayserili H, Lurie IW, Schinzel A, Baumer A. Epigenetic mutations of the imprinted IGF2-H19 domain in Silver-Russell syndrome (SRS): results from a large cohort of patients with SRS and SRS-like phenotypes. J Med Genet 2009 Mar;46(3):192-7. 
(10) Arney KL. H19 and Igf2--enhancing the confusion? Trends Genet 2003 Jan;19(1):1723.

(11) Bell AC, Felsenfeld G. Methylation of a CTCF-dependent boundary controls imprinted expression of the Igf2 gene. Nature 2000 May 25;405(6785):482-5.

(12) Tost J, Dunker J, Gut IG. Analysis and quantification of multiple methylation variable positions in CpG islands by Pyrosequencing. Biotechniques 2003 Jul;35(1):152-6.

(13) Mackay DJ, Callaway JL, Marks SM, White HE, Acerini CL, Boonen SE, Dayanikli P, Firth HV, Goodship JA, Haemers AP, Hahnemann JM, Kordonouri O, Masoud AF, Oestergaard E, Storr J, Ellard S, Hattersley AT, Robinson DO, Temple IK. Hypomethylation of multiple imprinted loci in individuals with transient neonatal diabetes is associated with mutations in ZFP57. Nat Genet 2008 Aug;40(8):949-51.

(14) Murphy R, Baptista J, Holly J, Umpleby AM, Ellard S, Harries LW, Crolla J, Cundy T, Hattersley AT. Severe intrauterine growth retardation and atypical diabetes associated with a translocation breakpoint disrupting regulation of the insulin-like growth factor 2 gene. J Clin Endocrinol Metab 2008 Nov;93(11):4373-80.

(15) Sparago A, Cerrato F, Vernucci M, Ferrero GB, Silengo MC, Riccio A. Microdeletions in the human H19 DMR result in loss of IGF2 imprinting and Beckwith-Wiedemann syndrome. Nat Genet 2004 Sep;36(9):958-60.

(16) Prawitt D, Enklaar T, Gartner-Rupprecht B, Spangenberg C, Oswald M, Lausch E, Schmidtke P, Reutzel D, Fees S, Lucito R, Korzon M, Brozek I, Limon J, Housman DE, Pelletier J, Zabel B. Microdeletion of target sites for insulator protein CTCF in a chromosome 11p15 imprinting center in Beckwith-Wiedemann syndrome and Wilms' tumor. Proc Natl Acad Sci U S A 2005 Mar 15;102(11):4085-90.

(17) Leighton PA, Saam JR, Ingram RS, Stewart CL, Tilghman SM. An enhancer deletion affects both H19 and Igf2 expression. Genes Dev 1995 Sep 1;9(17):2079-89.

The Corresponding Author has the right to grant on behalf of

all authors and does grant on behalf of all authors, an

exclusive licence (or non exclusive for government employees)

on a worldwide basis to the BMJ Publishing Group Ltd to permit

this article (if accepted) to be published in JMG and any

other BMJPGL products and sublicences such use and exploit all

subsidiary rights, as set out in our licence 
1 Table 1: clinical data for patients 1-4

\begin{tabular}{|c|c|c|c|c|}
\hline & 1 & 2 & 3 & 4 \\
\hline $\begin{array}{l}\text { Gender } \\
\text { Age }\end{array}$ & $\begin{array}{l}\text { Male } \\
14 \mathrm{y}\end{array}$ & $\begin{array}{l}\text { Male } \\
14 \mathrm{y}\end{array}$ & $\begin{array}{l}\text { Female } \\
7 \mathrm{~m}\end{array}$ & $\begin{array}{l}\text { Female } \\
31 \mathrm{y}\end{array}$ \\
\hline $\begin{array}{l}\text { Pregnancy } \\
\text { History of infertility/assisted } \\
\text { reproduction } \\
\text { Placental abnormality }\end{array}$ & NK & $\begin{array}{l}\text { No } \\
\text { "Poor condition" }\end{array}$ & $\begin{array}{l}\text { No } \\
\text { No }\end{array}$ & NK \\
\hline $\begin{array}{l}\text { Growth } \\
\text { Birth weight (weeks gestation) } \\
\text { Height (age) }\end{array}$ & $\begin{array}{l}2.1 \mathrm{~kg}\left(0.4^{\text {th }}-2^{\text {nd }}\right)(38 / 40) \\
84 \mathrm{~cm}\left(<0,4^{\text {th }}\right)(3 y) \\
163 \mathrm{~cm}\left(50^{\text {th }}-75^{\text {th }}\right)(14 y) \\
33.5 \mathrm{~cm}\left(25^{\text {th }}-50^{\text {th }}\right)(\text { birth })\end{array}$ & $\begin{array}{l}1.95 \mathrm{~kg}\left(0.4^{\text {th }}\right)(38 / 40) \\
60 \mathrm{~cm}\left(<<0.4^{\text {th }}\right)(7.5 \mathrm{~m}) \\
102 \mathrm{~cm}\left(2^{\text {nd }}-9^{\text {th }}\right)(4 y 10 \mathrm{~m}) \\
47.5 \mathrm{~cm}\left(91^{\mathrm{st}}-98^{\text {th }}\right)(7.5 \mathrm{~m})\end{array}$ & $\begin{array}{l}1.48 \mathrm{~kg}\left(0.4^{\text {th }}-2^{\text {nd }}\right)(35 / 40) \\
41.2 \mathrm{~cm}\left(<<0.4^{\text {th }}\right)(7 \mathrm{wk}) \\
52 \mathrm{~cm}\left(<<0.4^{\text {th }}\right)(6 \mathrm{~m}) \\
36 \mathrm{~cm}\left(50^{\text {th }}-75^{\text {th }}\right)(7 \mathrm{wk})\end{array}$ & $\begin{array}{l}1.25 \mathrm{~kg}\left(<<0.4^{\text {th }}\right)(40 / 40) \\
145 \mathrm{~cm}\left(<<0.4^{\text {th }}\right)(31 \mathrm{y}) \\
\text { NK }\end{array}$ \\
\hline $\begin{array}{l}\text { Congenital abnormalities } \\
\text { Male genital anomaly } \\
\text { Skeletal abnormality }\end{array}$ & $\begin{array}{l}\text { Cryptorchidism, inguinal } \\
\text { hernia } \\
\text { Delayed bone age at } 14 \mathrm{y}\end{array}$ & $\begin{array}{l}\text { No } \\
\text { No }\end{array}$ & $\begin{array}{l}\text { n/a } \\
\text { No }\end{array}$ & $\begin{array}{l}\mathrm{n} / \mathrm{a} \\
\text { No }\end{array}$ \\
\hline $\begin{array}{l}\text { Other problems } \\
\text { Psychomotor / speech delay }\end{array}$ & No & No & No & No \\
\hline
\end{tabular}




\begin{tabular}{|c|c|c|c|c|}
\hline Excessive sweating & No & Yes & No & No \\
\hline Hypoglycaemia & No & In infancy & No & No \\
\hline Feeding difficulties & Yes & Yes & Yes & No \\
\hline Gastrointestinal reflux & No & Yes & No & No \\
\hline \multicolumn{5}{|l|}{ Craniofacial features } \\
\hline Triangular face & Yes & Yes & Yes & No \\
\hline Frontal bossing & Yes & Yes & Yes & No \\
\hline Micro/retrognathia & Yes & No & No & No \\
\hline Irregular/crowded teeth & NK & No & $\mathrm{n} / \mathrm{a}$ & No \\
\hline Small teeth & NK & Yes & $\mathrm{n} / \mathrm{a}$ & No \\
\hline Downturned corners of mouth & Yes & Yes & Yes & No \\
\hline Thin upper lip & Yes & No & No & No \\
\hline Low set/posteriorly-rotated ears & Yes & low set & Yes & No \\
\hline Epicanthus & Yes & NK & NK & No \\
\hline \multicolumn{5}{|l|}{ Other clinical signs } \\
\hline 5th finger clinodactyly & Yes & Yes & Yes & No \\
\hline Camptodactyly & No & No & No & No \\
\hline Joint contractures & No & No & No & No \\
\hline Café au lait patches & No & No & No & No \\
\hline
\end{tabular}




\begin{tabular}{|l|l|l|l|l|}
\hline Other & Multiple haemangiomata & & Atypical diabetes \\
& & & Lactation failure \\
\hline
\end{tabular}

1

2 NK, not known; n/a, not applicable; y, years; m, months; wk, weeks 


\section{$1 \quad$ FIGURE LEGENDS}

2 Figure 1: genetic organization of the human H19-IGF2 region, and cytogenetic, genetic and

3 epigenetic analysis of patients 1-4. a. Sequence numbering according to human genome

4 release 18 of March 2006. Genes are represented by solid blue lines; putative enhancer

5 elements by dashed lines (meso: mesodermal enhancer, skm: skeletal muscle and

6 mesodermal enhancers, endo: endodermal enhancer); H19-ICR and IGF2P0 regions are

7 marked in solid blue with a "lollipop". FISH probes are marked in solid black. The triangular

8 arrowheads mark MLPA probes deleted in patient 1. MLPA probes written in blue contain a

9 HhaI recognition site. Solid red lines indicate the location of deletions in patients 1-3 mapped

10 by aCGH and dashed red line indicate translocation breakpoint in patient 4 mapped by FISH.

11 b. Pyrograms for patients 1, 3 and 4 illustrating allele quantification of bisulfite-induced C/T

12 polymorphisms within $H 19$ and IGF2P0. NC: normal control. Each table cell contains a

13 representative pyrogram of the first $\mathrm{C} / \mathrm{T}$ polymorphism. Figures above each pyrogram

14 indicate the proportions of methylated and unmethylated product. c. Electropherogram of

15 microsatellite D11S4046. Middle panel: patient 1; upper panel: father; lower panel: mother.

16 d. FISH analysis of patient 3. Upper panel: W12-1875E5 (red) retained on 11p; lower panel:

17 W12-1660M14 (red) which is transferred to 11q. The centromere probe D11Z2 (green)

18 hybridizes to both normal and derivative chromosomes 11. 

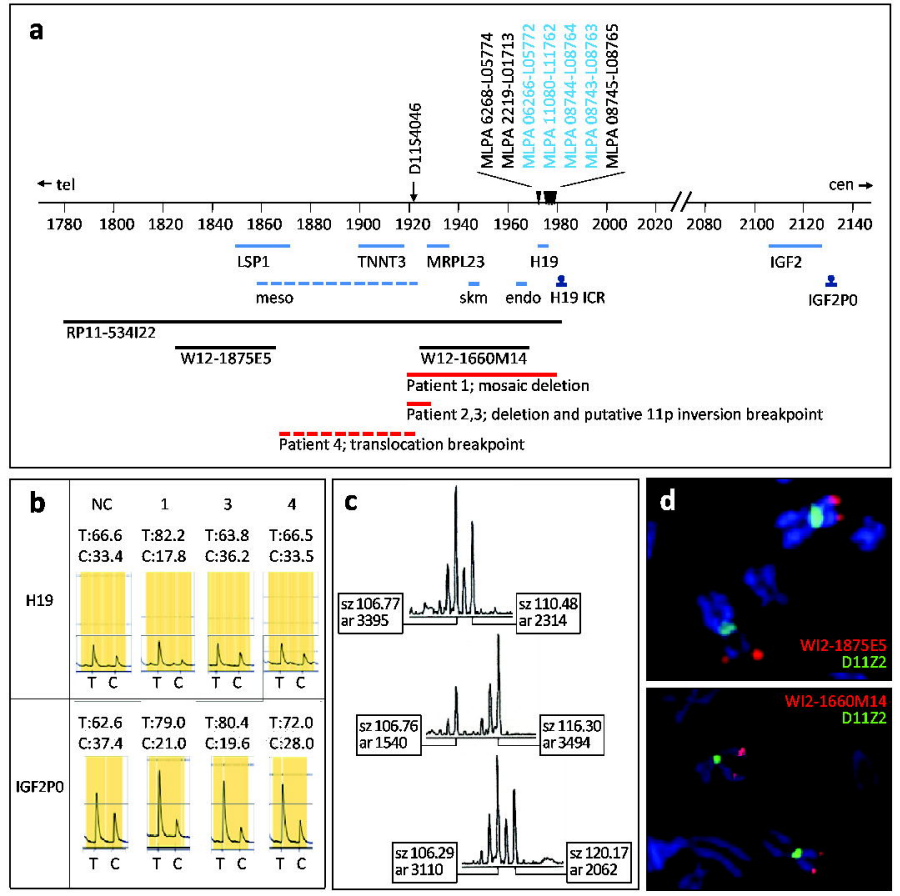